\title{
Analisa Kualitas Crude Palm Oil (CPO) dan Usulan Perbaikan Menggunakan Metode Tree Diagram di PT. Johan Sentosa Bangkinang
}

\author{
Denny Astrie Anggraini, Warid Wijaya \\ Program Studi Teknik Industri, Fakultas Teknik, Universitas Muhammadiyah Riau \\ Jl. Tuanku Tambusai Ujung Pekanbaru \\ E-mail:dennyastrie@umri.ac.id,waridwijaya@gmail.com
}

\begin{abstract}
Abstrak
PT.Johan Sentosa adalah perusahaan perkebunan dan industri kelapa sawit yang salah satu produknya adalah minyak kelapa sawit (CPO). Perusahaan berusaha untuk mendapatkan hasil minyak CPO berkualitas tinggi agar dapat memenuhi dan memberikan kepuasan pada pelanggannya. Namun masih ditemukan permasalahan terhadap kualitas minyak CPO yang dihasilkan, yaitu tingginya kadar ALB dan kadar air serta rendahnya rendemen. Maka dari itu dilakukan identifikasi untuk mencari akar penyebab rendahnya kualitas CPO serta tindak perbaikan kualitas minyak crude palm oil (CPO) menggunakan tree diagram. Akar penyebab dari permasalahan itu antara lain : pemanen belum mengetahui rotasi panen, keterlambatan pengiriman tandan buah segar (TBS) ke pabrik, dan kurang inspeksi di pabrik pada peralatan/mesin produksi. Oleh karena itu tindakan perbaikan yang dapat dilakukan antara lain : memberikan pelatihan/penyuluhan oleh divisi kebun tentang rotasi panen yang tepat, mengoptimalkan work intruction/standart operation prosedur untuk karyawan dan mengadakan training/ penyuluhan.
\end{abstract}

Kata kunci: Analisis Pengendalian Kualitas, CPO, Tree Diagram

\section{Pendahuluan}

\subsection{Latar Belakamg}

Kualitas minyak kelapa sawit ditentukan oleh kadar asam lemak bebas, kadar air dan rendemen yang sudah distandarkan dan berlaku di PT.Johan Sentosa Bangkinang. Standar kualitas pada tabel 1 berikut dibuat bertujuan untuk memenuhi keinginan dan kriteria konsumen. Oleh karena itu agar standar kualitas dapat tercapai maka diperlukan pemantauan kualitas dari segala hal yang berkaitan dengan proses produksi minyak kelapa sawit. Salah satu divisi yang berhubungan dengan pemantauan kualitas adalah laboratorium pabrik kelapa sawit. Adapun tugas laboratorium pabrik sawit di perusahaan ini adalah sebagai berikut :

1. Memeriksa kualitas Crude Palm Oil (CPO) dan Kernel.

2. Menghitung berapa banyak hasil produksi yang hilang (loses) selama proses produksi.

3. Menganalisa raw water (bahan baku air, yang pada umumnya diperoleh dari pembuatan waduk konvensional atau dari air sungai) dan boiler water.
4. Memonitor perubahan anaerobik dengan melakukan analisa rutin limbah Palm Mill Effluent (PME).

Berikut adalah tabel data standar kualitas crude palm oil (CPO) yang ditetapkan perusahaan :

Tabel 1.

Data Standar Kualitas CPO

\begin{tabular}{clc}
\hline No & \multicolumn{1}{c}{ Karakteristik } & Standar $(\%)$ \\
\hline 1 & Kadar Asam Lemak Bebas (ALB) & $<3.25$ \\
2 & Kadar Air & $<0.10$ \\
3 & Rendemen & $>23$ \\
\hline
\end{tabular}

Untuk memastikan kualitas CPO yang dihasilkan maka laboratorium melakukan pengambilan sampel setiap hari, dengan volume berkisar $200 \mathrm{ml}$. Jenis analisa yang dilakukan adalah penentuan kandungan asam lemak bebas, penentuan kadar air dan rendemen.

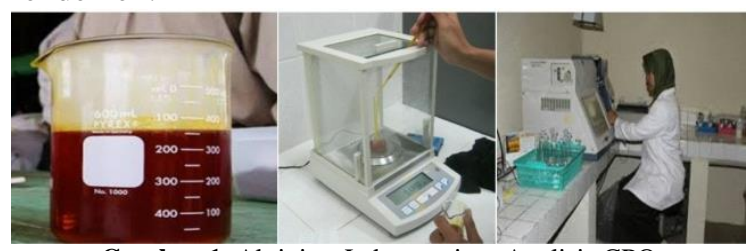

Gambar 1. Aktivitas Laboratorium Analisis CPO 
Namun saat ini PT. Johan Sentosa mengalami permasalahan dimana crude palm oil (CPO) yang dihasilkan tidak mencapai standar kualitas yang sudah distandarkan oleh perusahaan sebagai berikut:

Tabel 2.

Data Pengamatan CPO Bulan Maret-Mei 2017

\begin{tabular}{lccc}
\hline Bulan & $\begin{array}{c}\text { Kadar ALB } \\
(\%)\end{array}$ & $\begin{array}{c}\text { Kriteria } \\
\text { Kadar Air } \\
(\%)\end{array}$ & $\begin{array}{c}\text { Rendemen } \\
(\%)\end{array}$ \\
\hline Maret & 3.55 & 0.37 & 20.75 \\
April & 3.52 & 0.26 & 19.36 \\
Mei & 3.76 & 0.24 & 19.55 \\
Standar (\%) & $<3.25$ & $<0.10$ & $>23$ \\
\hline
\end{tabular}

Oleh karena itu pada penelitian ini akan dilakukan analisa terhadap kualitas CPO yang dihasilkan dengan mengidentifikasi penyebab terjadinya permasalahan serta diberikan usulan perbaikan dengan menggunakan tree diagram.

\subsection{Landasan Teori}

\section{A. Minyak Kelapa Sawit}

Minyak kelapa sawit adalah minyak yang dihasilkan dari inti kelapa sawit (palm kernel oil). Minyak kelapa sawit terutama dikenal sebagai bahan mentah minyak dan lemak pangan yang digunakan untuk menghasilkan minyak goreng, shortening, margarin, dan minyak makan lainnya. Dengan kandungan karoten yang tinggi, minyak sawit merupakan sumber provitamin A yang murah dibandingkan dengan bahan baku lainnya. Minyak sawit dihasilkan dari proses ekstraksi bagian sabut buah dan biji buah kelapa sawit. Miinyak yang dihasilkan dari bagian kulit atau sabut tersebut dikenal dengan nama Crude Palm Oil (CPO) dan bagian biji buahnya disebut Palm Kernel Oil (PKO).

\section{B. Asam Lemak Bebas (Free Fatty Acid)}

Asam lemak bebas merupakan fraksi bukan lemak yang dapat mempengaruhi kualitas minyak. Asam lemak bebas terbentuk karena proses oksidasi dan hidrolisa enzim selama pengolahan dan penyimpanan. Kadar asam lemak bebas yang tinggi akan menyebabkan turunnya kualitas minyak, misalnya menyebabkan ketengikan pada minyak, membuat rasanya tidak enak, terjadinya perubahan warna dan juga rendemen minyak menjadi turun.

\section{Kadar Air}

Tingginya kadar air akan menurunkan kualitas minyak yang dihasilkan yaitu minyak akan beraroma tidak sedap selama penyimpanan. Semakin sedikit kadar air yang terkandung dalam minyak semakin tinggi kualitas minyak yang dihasilkan.

\section{Rendemen}

Istilah yang tidak dapat dipisahkan dari kelapa sawit adalah rendemen, rendemen secara umum didefinisikan sebagai persen jumlah yang dapat dimanfaatkan dari jumlah keseluruhan. Rendemen kelapa sawit menunjukkan berapa kandungan minyak sawit yang berada didalam buah sawit atau TBS. Agar jumlah rendemen dalam kelapa sawit tidak berkurang maka harus dilakukan usaha untuk menjaga agar kualitas rendemen tetap tinggi dengan memperhatikan saat TBS sebelum dipanen, pengangkutan TBS ke pabrik, penimbangan TBS dan Pabrikasi (pengolahan TBS di pabrik).

\section{E. Quality Control}

Quality control adalah pengendalian kualitas untuk mengukur ciri-ciri kualitas produk dan membandingkannya dengan spesifikasi atau persyaratan, pengendalian kualitas ini didasari oleh beberapa parameter uji dimana untuk setiap parameter uji terdapat prosedur yang telah distandarisasi dan divalidisasi kelayakannya.

\section{F. Metode Tree Diagram}

Tree diagram adalah metode yang digunakan untuk identifikasi penyebab suatu masalah. Analisis tree diagram dilakukan dengan membentuk pola pikir yang lebih terstruktur mengenai komponen sebab akibat yang berkaitan dengan masalah yang telah diprioritaskan. Metode ini dapat dijadikan sebagai saran perbaikan kualitas dan dapat diterapkan apabila sudah dilakukan identifikasi dan penentuan prioritas masalah. Selain itu tree diagram sebagai pemecah konsep masalah memiliki beberapa kegunaan dan dapat mengetahui masalah yang berhubungan sebab akibat masalah tersebut.

\subsection{Tujuan Penelitian}

Adapun tujuan dilakukan penelitian ini adalah :

a. Mengetahui penyebab tidak tercapainya standar kualitas crude palm oil (CPO) perusahaan.

b. Memberikan usulan perbaikan terhadap kualitas CPO untuk di evaluasi oleh pihak perusahaan.

\section{Methodologi}

Methodologi yang digunakan dalam penelitian ini terdiri dari beberapa tahap yaitu :

A. Tahap Studi Pendahuluan, meliputi :

1. Perumusan masalah yang akan diteliti.

2. Tinjauan pustaka dan tinjauan lapangan.

3. Permusan tujuan penelitian 
B. Tahap Identifikasi, meliputi :

1. Pemilihan metode yang akan digunakan.

2. Penentuan tempat penelitian.

3. Penentuan data yang dibutuhkan.

C. Tahap Pengolahan dan Analisa data, meliputi :

1. Menggunakan tree diagram untuk mencari akar penyebab rendahnya kualiatas CPO.

2. Melakukan pemecahan masalah untuk mencari tindak perbaikan yang tepat untuk mengatasi rendahnya kualitas $\mathrm{CPO}$

3. Menganalisa hasil pengolahan.

D. Tahap Penutup, meliputi : penarikan kesimpulan.

\section{Hasil dan Pembahasan}

Analisa kualitas sampel minyak kelapa sawit yang dilakukan di laboratorium terdiri dari analisa kadar asam lemak bebas (free fatty acid/FFA), kadar air (moist and impurities) dan rendemen minyak. Selama pengamatan sampel ditemukan ketidak sesuaian dimana crude palm oil (CPO) tidak mencapai kualitas standar perusahaan. Maka dari itu dalam pembahasan ini akan dilakukan analisa penyebab tidak tercapainya target kualitas crude palm oil (CPO), juga diberikan usulan perbaikan dengan menggunakan tree diagram.
Di tahapan ini untuk permasalahan yang akan dijadikan target perbaikan adalah sebagai berikut :

1. Tingginya asam lemak bebas (ALB).

2. Tingginya kadar air.

3. Rendahnya kadar rendemen.

\subsection{Kadar Asam Lemak Bebas (ALB)}

Berikut data asam lemak bebas (ALB) bulan Maret-Mei 2017.

Tabel 3.

Data Kadar ALB Bulan Maret-Mei 2017

\begin{tabular}{lcc}
\hline \multicolumn{1}{c}{ Bulan } & Kadar ALB (\%) & Standar Kualitas (\%) \\
\hline Maret & 3.55 & \\
April & 3.52 & $<3.25$ \\
Mei & 3.76 & \\
\hline
\end{tabular}

Dari tabel diatas dapat dilihat asam lemak bebas dalam konsentrasi tinggi yang terikut dalam minyak sawit sangat merugikan. Tingginya asam lemak bebas ini mengakibatkan kualitas minyak rendah. Maka dari itu dilakukan usaha pencegahan terbentuknya asam lemak bebas dalam minyak sawit. Tree diagram analisa tingginya asam lemak bebas dan tindakan perbaikan terhadap kualitas crude palm oil (CPO) dapat dilihat pada gambar 2 berikut :

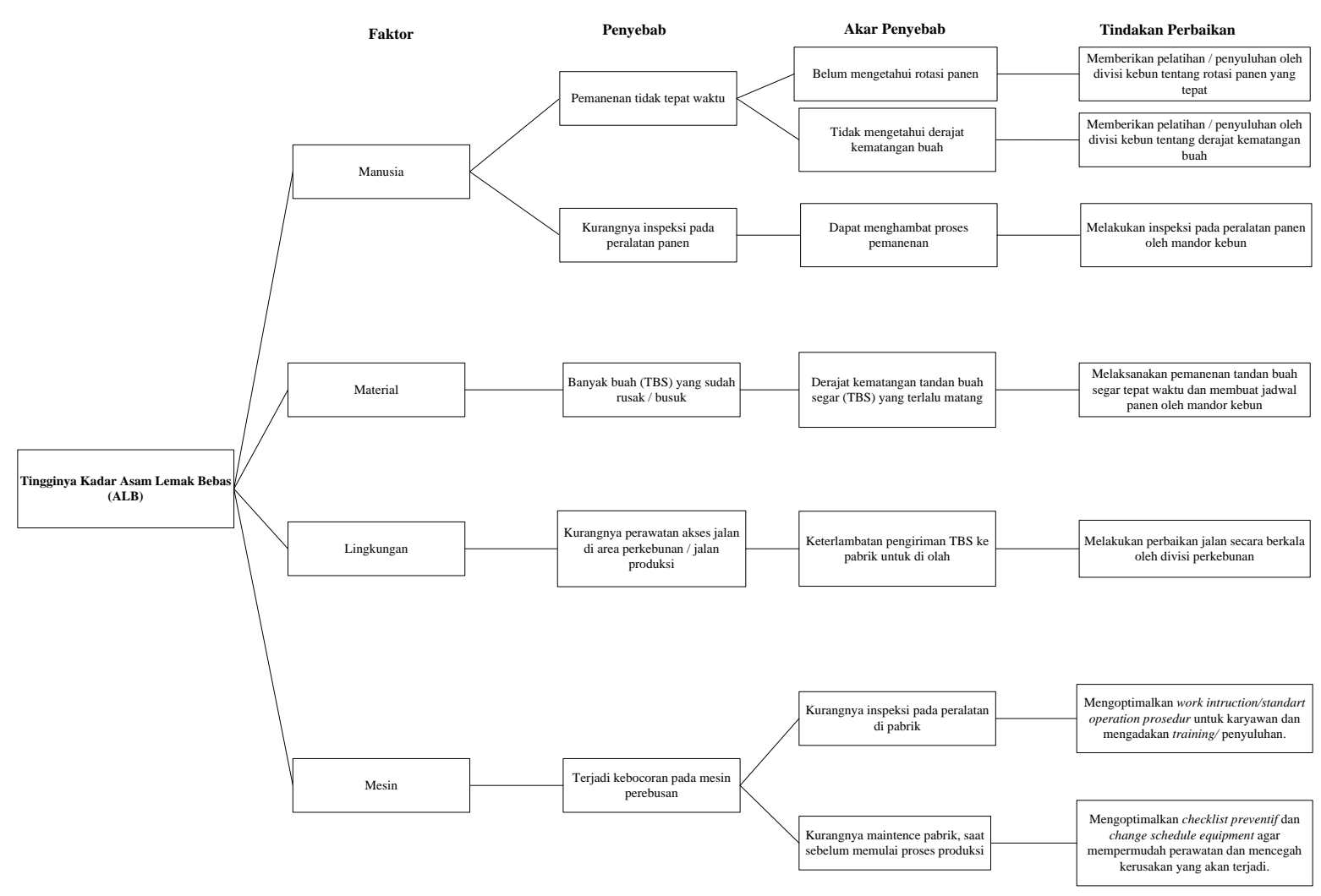

Gambar 2. Tree Diagram Analisa Tingginya Kadar Asam Lemak Bebas 


\subsection{Kadar Air}

Berikut data kadar air bulan Maret-Mei 2017 :

Tabel 4.

Data Kadar Air Bulan Maret-Mei 2017

\begin{tabular}{lcc}
\hline Bulan & Kadar Air (\%) & Standar Kualitas (\%) \\
\hline Maret & 0.37 & \\
April & 0.26 & $<0.10$ \\
Mei & 0.24 & \\
\hline
\end{tabular}

Dari tabel diatas dapat dilihat kadar air dalam konsentrasi tinggi yang terikut dalam minyak sawit sangat merugikan. Tingginya kadar air akan menurunkan kualitas minyak yang dihasilkan yaitu minyak akan beraroma tidak sedap selama penyimpanan. Semakin sedikit kadar air yang terkandung dalam minyak semakin tinggi kualitas minyak yang dihasilkan. Maka dari itu dilakukan usaha pencegahan tingginya kadar air dalam minyak sawit.

Tree diagram analisa tingginya kadar air dan tindakan perbaikan terhadap kualitas crude palm oil (CPO) dapat dilihat pada gambar 3.

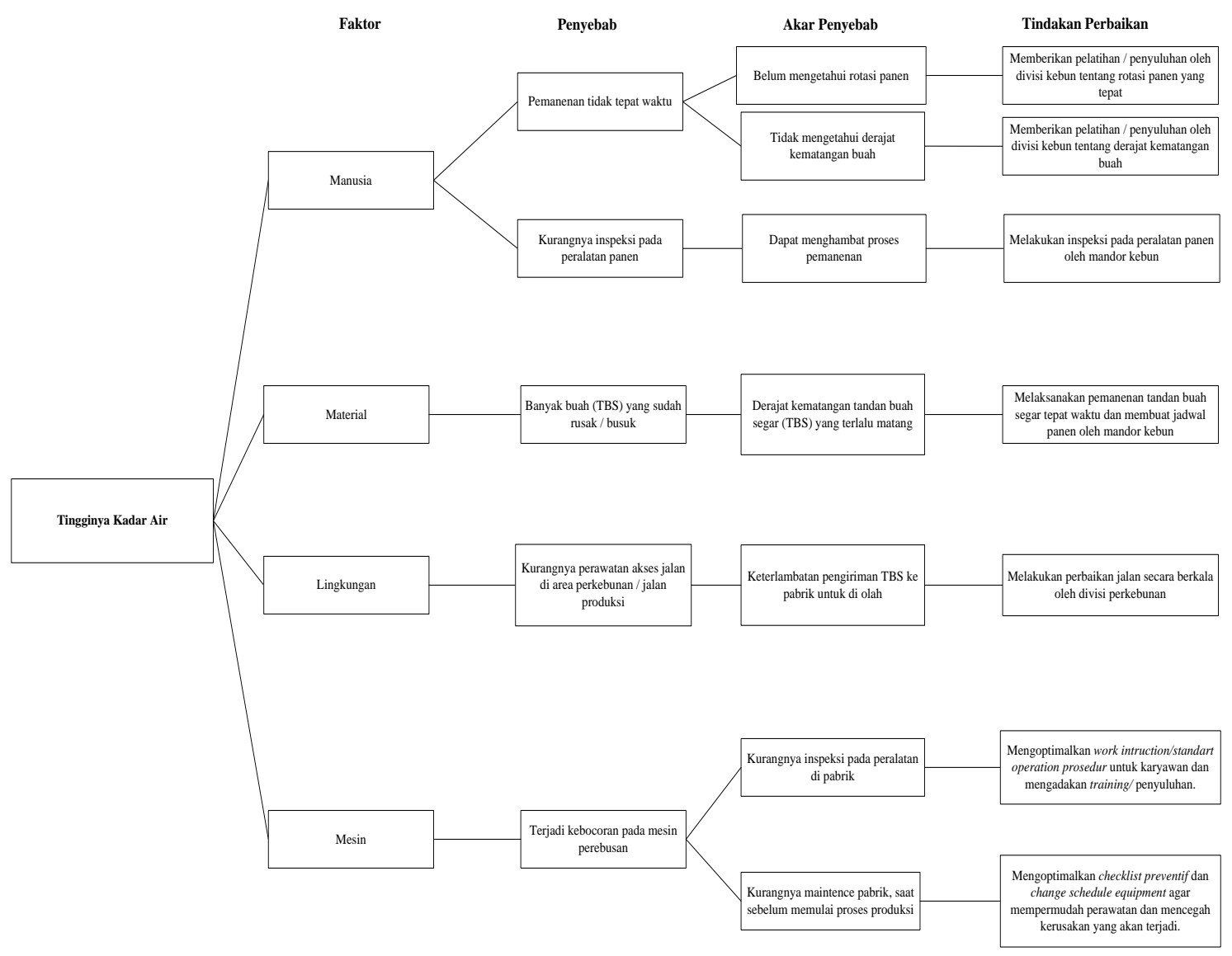

Gambar 3. Tree Diagram Analisa Tngginya Kadar Air

\subsection{Rendemen}

Berikut data rendemen bulan Maret-Mei 2017 :

Tabel 5.

Data Rendemen Bulan Maret-Mei 2017

\begin{tabular}{lcc}
\hline Bulan & Rendemen (\%) & Standar Kualitas (\%) \\
\hline Maret & 20.75 & \\
April & 19.36 & $>23$ \\
Mei & 19.55 & \\
\hline
\end{tabular}

Dari tabel diatas dapat dilihat kadar rendemen selama bulan maret-mei 2017 tidak memenuhi standar kualitas.

Rendemen perlu diketahui guna mengetahui seberapa besar pabrik dalam memproduksi minyak kelapa sawit. Hal ini berguna untuk pabrik karena rendemen yang diketahui dapat menjadi kontrol terhdap peningkatan kualitas pabrik dalam memproduksi minyak kelapa sawit, maka dari itu dilakukan usaha meningkatkan rendemen.

SURYA TEKNIKA Vol. 5 No. 2, Desember $2017: 57$ - 62 . 
Berikut tree diagram analisa rendahnya kadar rendemen dan tindakan perbaikan terhadap kualitas crude palm oil (CPO) :

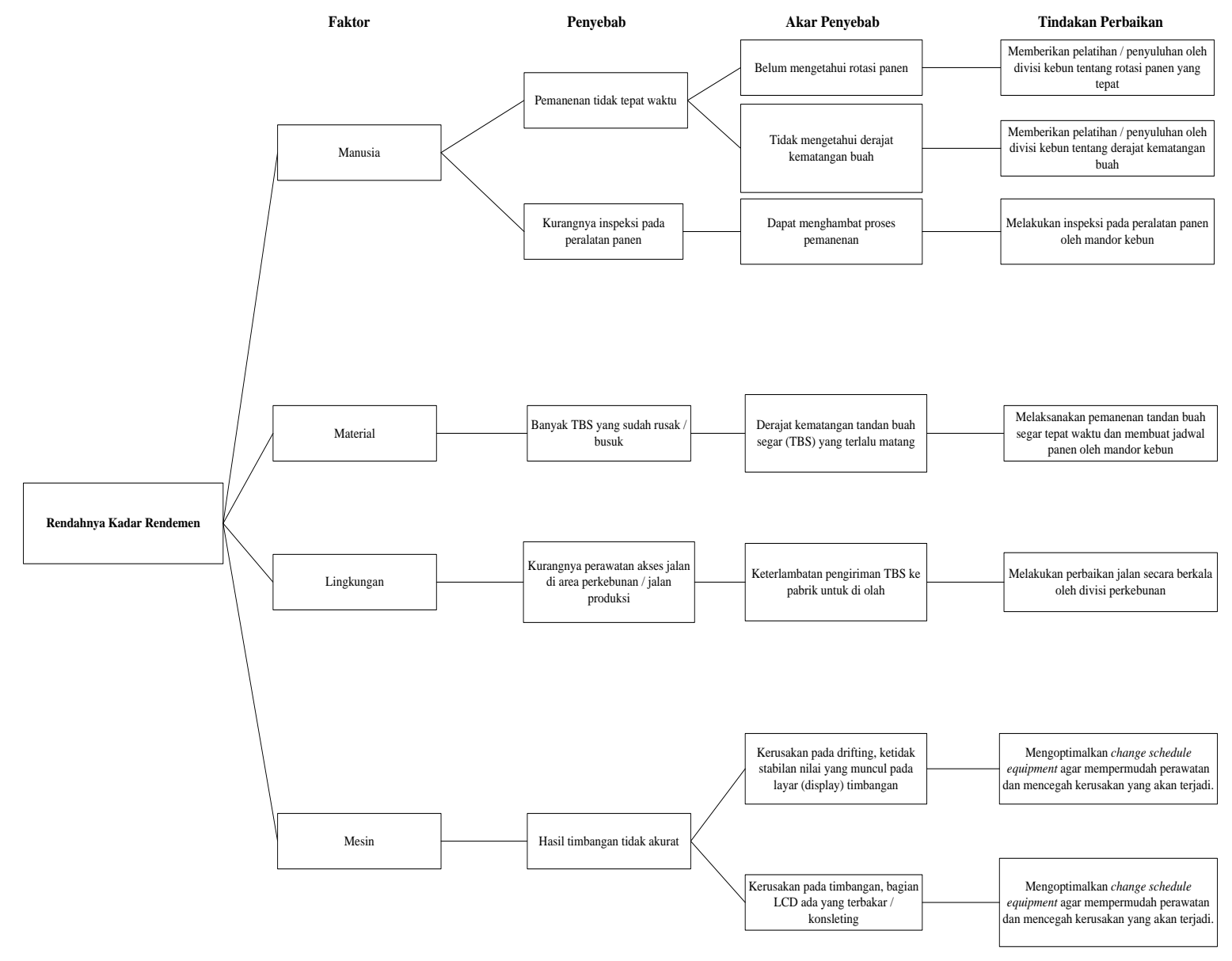

Gambar 4. Tree diagram Analisa Rendahnya Rendemen

\subsection{Rekomendasi}

Dari hasil pembahasan penyebab tingginya kadar ALB dan kadar air menggunakan tree diagram, maka dapat direkomendasikan usulan perbaikan sebagai berikut :

1. Faktor manusia

a. Memberikan pelatihan oleh divisi kebun tentang rotasi pemanenan buah kelapa sawit.

b. Memberikan pelatihan oleh divisi kebun tentang derajat kematangan TBS terhadap pekerja kebun.

2. Faktor material (Bahan Baku)

a. Melaksanakan pemanenan tandan buah segar tepat waktu dan membuat jadwal panen oleh mandor kebun, agar bahan baku tidak terlalu kematangan saat panen.

3. Faktor lingkungan

a. Melakukan perbaikan jalan di area perkebunan secara berkala oleh divisi kebun.
4. Faktor mesin

a. Mengoptimalkan work intruction/standart operation prosedur untuk maintenence dan mengadakan training (penyuluhan).

b. Mengoptimalkan checklist preventif dan change schedule equipment agar mempermudah perawatan dan mencegah kerusakan yang terjadi.

Dari hasil pembahasan penyebab rendahnya kadar rendemen menggunakan metode tree diagram, maka dapat direkomendasikan usulan perbaikan sebagai berikut :

1. Faktor manusia.

a. Memberikan pelatihan oleh divisi kebun tentang rotasi panen yang tepat

b. Memberikan pelatihan oleh divisi kebun tentang sistem panen

2. Faktor material.

SURYA TEKNIKA Vol. 5 No. 2, Desember $2017: 57$ - 62 . 
a. Mengoptimalkan pemanenan tandan buah segar (TBS) tepat waktu, untuk mendapatkan rendemen yang berkualitas.

3. Faktor lingkungan.

a. Melakukan perbaikan jalan di area perkebunan secara berkala oleh divisi kebun.

4. Faktor mesin

a. Mengoptimalkan change schedule equipment agar mempermudah perawatan dan mencegah kerusakan yang akan terjadi.

b. Mengoptimalkan change schedule equipment agar mempermudah perawatan dan mencegah kerusakan yang akan terjadi.

\section{Simpulan}

Beberapa kesimpulan yang dapat diambil dari pelaksanaan penelitian ini adalah sebagai berikut :

1. Akar penyebab dari permasalahan itu antara lain : pemanen belum mengetahui rotasi panen, keterlambatan pengiriman tandan buah segar (TBS) ke pabrik, dan kurang inspeksi di pabrik pada peralatan/mesin produksi.

2. Rencana tindakan perbaikan yang dapat dilakukan antara lain : memberikan pelatihan/penyuluhan oleh divisi kebun tentang rotasi panen yang tepat, mengoptimalkan work intruction/standart operation prosedur untuk karyawan dan mengadakan training/ penyuluhan.

\section{Daftar Pustaka}

[1.] Arif, Muhammad. 2010. Analisis Konsistensi Mutu Dan Rendemen Crude Palm Oil (CPO) Di Pabrik Kelapa Sawit Tanjung Seumantoh PTPN 1 Nanggoroe Aceh Darussalam. Departemen Teknologi Pertanian Fakultas Pertanian Universitas Sumatera Utara (10 September 2017).

[2] Hidayati, Annisa. 2014. Memahami Analisis Pohon Masalah. Fakultas Teknik Universitas airlangga Surabaya (20 Agustus 2017).

[3] Marunduri, Firman. 2013. Pengaruh Waktu Inap CPO Pada Storage Tank Terhadap Kadar Asam Lemak Bebas, Kadar Air Dan Kadar Kotoran Di PTPN III Tebing Tinggi PKS Kebun Rambutan. Departemen Kimia. Fakultas Matematika Dan Ilmu Pengetahuan Alam. Universitas Sumatera Utara (26 September 2017).

[4] Muhammad, Hasby. 2010. Penggunaan Pohon Keputusan dalam Teori Keputusan Diambil dari http://informatika.stei.itb.ac.id/ rinaldi.munir /Matdis/2010 (05 September 2017).

[5] Panduan Kerja Praktek Teknik Industri Universitas Muhammadiyah Riau (2017).

[6] Rizal, Putra. 2013. Kinerja Perubahan Kadar Asam Lemak Bebas Dan Kadar Minyak Kelapa Sawit Akibat Penundaan Waktu Pengolahan. Fakultas Teknologi Pertanian Universitas Sriwijaya (11 September 2017).

[7] Zakki, Falani. 2014. Decision Tree (Pohon Keputusan). Diambil Dari: <http://mfile.narotama.ac.id/files/Zakki\%20F alani/Konsep\%20Data\%20Mining /Algoritma\%20C4.pdf> (05 Sepember 2017).

SURYA TEKNIKA Vol. 5 No. 2, Desember $2017: 57$ - 62 . 